\title{
A STUDY ON TREATMENT COMPLIANCE AMONG METHADONE CLIENTS IN MMTP PROGRAM TUTH, NEPAL
}

\author{
Kabin Man Dangol, Manisha Chapagain and Pratikchya Tulachan
}

\begin{abstract}
Background: Since past 30 years, methadone has been used as a substitute therapy for opiate dependence because of its many advantages. It has cross-tolerance property and significantly effects to reduce drug injecting and it related behavior as well as lower the mortality in drug users with HIV infected.
\end{abstract}

Objective: The aim of this Study is to find out correlation between doses and dropout rate among Methadone Maintenance Treatment clients.

Method: 112 dropout methadone clients who had enrolled in the MMTP program in Department of Psychiatry, TUTH Maharajgunj within one year period assessed their final doses before dropout from the program.

Result: The mean initial and last (final or exit) dose of methadone in Dose Stable group (DSG) is $32.44 \pm 9.2 \mathrm{mg}$, in Dose Increased group (DIG) $36.25 \pm 8.6 \mathrm{mg}$ and $47.50 \pm 11.2 \mathrm{mg}$, and in Dose Decreased group (DDG) $37.63 \pm 7.4 \mathrm{mg}$ and $15.66 \pm 10.2 \mathrm{mg}$ respectively.

Conclusion: The lower the doses of methadone, the higher risk of dropout among the clients of the Methadone Maintenance program

Key words: Methadone, Substitution Therapy, Opiate dependence,

\section{Introduction}

Methadone Hydrochloride, a synthetic opioid that works primarily at the $\mu$ - receptor of the brain. It was developed medically as an analgesic to treat pain in the 1940s. It is the best researched oral substituted therapy for opioid dependence. It is, still prescribed widely for the management of pain in America, Australia and Europe. ${ }^{1-6}$

Experience in the past 30 years has clearly demonstrated that methadone maintenance treatment is the most effective intervention method to reduce illicit opiate use more than no treatment ${ }^{7-11}$, drug free treatment ${ }^{12}$ placebo medication $^{13,14}$, or detoxification ${ }^{15-17}$ in clinical controlled trials in different research groups and different cultural settings.

There are many aspects to use methadone as a substitute therapy for opiate dependence because of various pharmacological features of opioid. In adequate doses $(20 \mathrm{mg}$ to $>100$ mg) methadone prevents or reverses withdrawal symptoms. ${ }^{18}$ It remains effective for approximately 24 hours and requiring a single daily dose rather than the more frequent administration of multiple times daily ${ }^{19}$. It has cross-tolerance property to block the euphoric effects of heroin and discourages to use illicit drugs thereby in 
users relieving desire to seek heroin this allows the opportunity to engage in normal daily activities and work rehabilitation.

Methadone treatment has a significant effect to reduce drug injecting behaviors, drug related criminal behavioral, HIV infection and improve relationships within the families among heroine users ${ }^{20}$ as well as improve adherence to the ART regimen and lower the mortality opioid dependence with HIV infected $^{21}$. Mortality from all causes is manyfold lower in methadone-treated patients than in untreated opioid addicts.

In contrast, inappropriate overdosing and under dosing of methadone may lead to sever adverse events including sedation, respiratory depression and cardiac arrhythmias. ${ }^{22}$ In addition, the withdrawal of methadone is longer than of heroin. Many clients require continuing the treatment a long time. There is risk of abuse. Moreover it is not a cure for opiate addiction. However it suppresses withdrawal symptoms, lessens the craving for narcotics, facilitates interpersonal interactions and strengthens motivations, changing lifestyle, and breaking the cycle of life patterns and stress reactions underlying relapse.

\section{Method}

\section{Sample}

Participants were all methadone clients who had enrolled in the program within one year but dropped out from the program. The total numbers of client were 112. All the participants were taken from the MMTP program of Department of Psychiatry, Tribhuvan University Teaching Hospital Maharajgunj.

In inclusion criteria the methadone clients who were had enrolled in methadone program but dropped out for more than 15 days.

\section{Data analysis}

The last doses of the clients were considered to be the dose of the client related to dropout from the program. Doses were divided into three groups: 1) Dose stable group (DSG): whose doses were neither increased nor decreased frequently and throughout the treatment program the dose was stable in same dose. 2) Dose decrease group (DDG): those doses were decreased to last dose from initial dose. \& 3) Dose increased group (DIG): those doses were increased to last dose from initial dose

The aim of study was find out the relation between the doses of methadone and dropout rate or retention in the program.

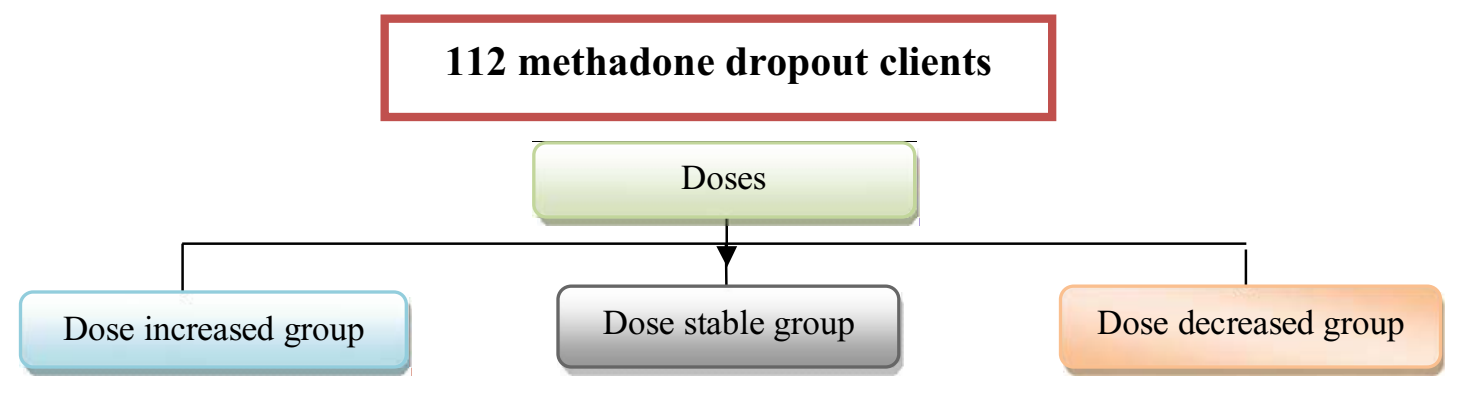

\section{Result}

Of the 112 dropout clients, 43 (38.4\%) were in DSG, 57 (50.9\%) in DDG and $12(10.7 \%)$ and in DIG (Table 1). The mean age of DSG was $29.44 \pm 5.6$ years; male $36.6 \%$, female 
$1.8 \%$; the mean initial and last dose was $32.44 \pm 9.2 \mathrm{mg}$. The mean age of DDG group was $29.58 \pm 5.4$ years; male $49.1 \%$ and female $1.8 \%$, the mean initial dose $37.63 \pm 7.4 \mathrm{mg}$ and last (exit) dose $15.66 \pm 10.2 \mathrm{mg}$. In DIG the mean age was $32.08 \pm 6.3$ years, male $9.8 \%$ and female
$0.9 \%$, the mean initial dose $36.25 \pm 8.6 \mathrm{mg}$ and last (exit) dose $47.50 \pm 11.2 \mathrm{mg}$.

The mean retaining period in the maintenance treatment was: DSG $22.30 \pm 36.1$ days; in DDG 78.26 \pm 63.5 days, and in DIG $58.0 \pm 51.2$ days

Table 1 Summary of baseline characteristics of drop out methadone Clients

\begin{tabular}{|c|c|c|c|c|c|}
\hline Baseline characteristics & $n$ & $\min$ & $\max$ & Mean & $\begin{array}{l}\text { Std } \\
\text { Deviation }\end{array}$ \\
\hline \multicolumn{6}{|l|}{$\overline{\text { Age (years) }}$} \\
\hline $\begin{array}{l}\text { In Total case } \\
\text { In groups }\end{array}$ & 112 & 21 & 49 & 29.77 & 5.6 \\
\hline Stable group & 43 & 21 & 45 & 29.44 & 5.6 \\
\hline Decrease group & 57 & 21 & 47 & 29.53 & 5.4 \\
\hline Increase group & 12 & 24 & 49 & 32.08 & 6.3 \\
\hline Gender ( $\%$ in total cases) & \multicolumn{2}{|c|}{ male $(n \%)$} & \multicolumn{3}{|c|}{ Female $(n \%)$} \\
\hline Stable group & \multicolumn{2}{|c|}{36.6} & \multicolumn{2}{|l|}{1.8} & \\
\hline Decrease group & \multicolumn{2}{|l|}{9.1} & \multicolumn{2}{|l|}{1.8} & \\
\hline Increase group & \multicolumn{2}{|l|}{9.8} & \multicolumn{2}{|l|}{0.9} & \\
\hline Dropout rate & \multicolumn{2}{|c|}{$(n \%)$} & & & \\
\hline Stable group & \multicolumn{2}{|c|}{38.4} & & & \\
\hline Decrease group & \multicolumn{2}{|l|}{50.9} & & & \\
\hline \multirow[t]{2}{*}{ Increase group } & \multicolumn{2}{|l|}{10.7} & & & \\
\hline & $n$ & $\min$ & $\max$ & Mean & Std \\
\hline \multicolumn{6}{|l|}{ Initial Dose (mg) } \\
\hline In total cases & \multirow[t]{4}{*}{112} & 560 & 35.49 & 8.5 & \\
\hline Stable group & & 560 & 32.44 & 9.2 & \\
\hline Decrease group & & 15 & 60 & 37.63 & 7.4 \\
\hline Increase group & & 25 & 55 & 36.25 & 8.6 \\
\hline \multicolumn{6}{|l|}{ Exit (last) dose (mg) } \\
\hline In total cases & \multirow[t]{4}{*}{112} & 365 & 25.51 & 14.8 & \\
\hline Stable group & & 560 & 32.44 & 9.2 & \\
\hline Decrease group & & 335 & 15.66 & 10.2 & \\
\hline Increase group & & 30 & 65 & 47.50 & 11.2 \\
\hline \multicolumn{6}{|c|}{ Period of Maintenance (days) } \\
\hline In total cases & \multirow[t]{4}{*}{112} & 1224 & 54.61 & 59.0 & \\
\hline Stable group & & 1182 & 22.30 & 36.1 & \\
\hline Decrease group & & 5224 & 78.26 & 63.5 & \\
\hline Increase group & & 3140 & 58.00 & 51.2 & \\
\hline
\end{tabular}



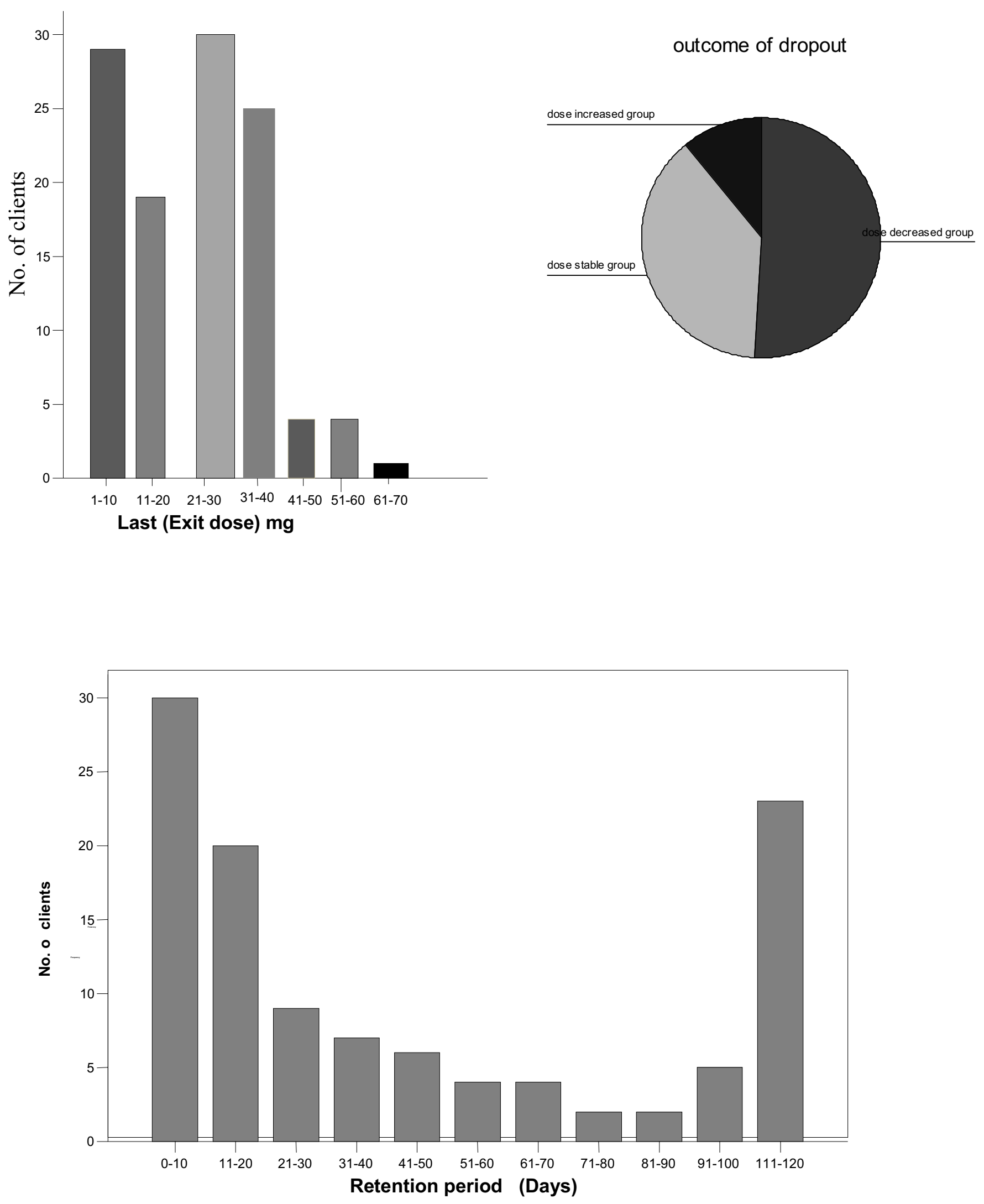


\section{Discussion}

Retention is a key for successful MMT program. Many studies have found that methadone dose is an important factor that can influence retention in methadone treatment. A meta-analysis of randomized, controlled, double-blind clinical trials found that a dose of $50 \mathrm{mg} /$ day was associated with higher retention rates ${ }^{23,}{ }^{24}$ concluded that an adequate methadone dose, on average, should be above $60 \mathrm{mg}$ to be effective. A randomized trial found that high-dose methadone treatment resulted in longer retention in MMT. Other studies also that found higher methadone doses were associated with higher retention rates. $25,26,27,28$ Our study also confirms this relationship among Nepalese drug users, and to identify other correlates of retention. Our main finding is that the lower the dose of methadone the higher the risk of dropout among MMT clients. In our study, among 112 dropout clients $50.9 \%$ were from DDG. In compare to DSG (38.4\%), DIG clients were very few in drop out $(10.7 \%)$

The results suggest that higher doses can achieve better retention rates, and that there is a positive dose-response relationship between methadone dose and client retention.

The National Institutes of Health (NIH) expert panel recommended a daily methadone dose of at least $60 \mathrm{mg}$ as a best practice for successful methadone maintenance. ${ }^{29}$. The General Accounting Office reviewed 24 methadone maintenance clinics, based on 5600 active clients, and concluded that the minimally effective dose was $50 \mathrm{mg} .{ }^{29}$

\section{Limitation of study}

This study was conducted after one year of starting the MMT program and it was beginning phase as well as the staffs might not be well trained to keep records of the clients' dose properly. The awareness and information about methadone among drug users might not have adequate, rumor among the drug users about side effects of methadone and in initial phase of the program the clients' dose recording system was manual and hand writing, which might increase the risk of errors in maintain the clients' dose record.

\section{Acknowledgement}

All staffs of the MMT program who helped to provide the required information and data for analysis.

\section{References}

1. Mattick RP, Breen $\mathbf{C}$, Kimber J , Davoli M. Methadone maintenance therapy versus no opioid replacement therapy for opioid dependence

2. Cooper J, Altman F, Brown, B, Czechowicz D. Research on thetreatment of narcotic addiction: State of the art. Rockville, MD: National Institute on Drug Abuse, 1983.

3. Gerstein D, Harwood H. Treating drug problems Volume 1: study of effectiveness and financing of public and private drug treatment systems. Washington, DC: National Academy Press, 1990.

4. Hargreaves W. Methadone dosage and duration for maintenance treatment.. In: J Cooper, F Altman, B Brown, D Czechowicz editor(s). Research on the treatment of narcotic addiction: State of the art. Rockville, MD: National Institute on Drug Abuse, 1983.

5. Mattick RP, Hall W. A treatment outline for approaches to opioid dependence: Quality assurance project. Canberra: Australian Government Publishing Service, 1993

6. Ward J, Mattick RP, Hall W. Key issues in methadone maintenance treatment. Sydney: New South Wales University Press, 1992. 
7. Dole V, Robinson J, Orraca J, Towns E, Searcy P, Caine E. Methadone treatment of randomly selected criminal addicts. New England Journal of Medicine 1969;280:1372-5.

8. Yancovitz S, Des Jarlais D, Peskoe Peyser N, Drew E, Friedman $P$, Trigg $H$, et al. A randomised trial of an interim methadone maintenance clinic. Am J of Pub Health 1991; 81:1185-91.

9. Dolan KA, Shearer J, MacDonald M, Mattick RP, Hall W, Wodak A. A randomised controlled trial of methadone maintenance treatment versus wait list control in an Australian prison system.Drug and Alcohol Dependence 2003;72:59-65.

10. Schwartz RP, Highfield DA, Jaffe JH, Brady JV, Butler CB, Rouse CO, et al. A randomised controlled trial of interim methadonemaintenance. Archives of General Psychiatry 2006;63:102-9.

11. Kinlock TW, Gordon MS, Schwartz RP, O'Grady K, Fitzgerald TT, Wilson M. A randomised clinical trial of methadone maintenance for prisoners: Results at 1 month post release. Drug and Alcohol Dependence 2007;91:220-7.

12. Gunne L, Gronbladh L. The Swedish methadone maintenance program: A controlled study. Drug and Alcohol Dependence 1981;7: 249-56.

13. Newman R, Whitehill W. Double-blind comparison of methadone and placebo maintenance treatments of narcotic addicts in Hong Kong. Lancet 1979; September 8:485-8.

14. Strain E, Stitzer M, Leibson I, Bigelow G. Doseresponse effects of methadone in the treatment of opioid dependence. Ann Intern Med 1993;119:237.

15. Vanichseni S, Wongsuwan B, Choopanya K, Wongpanich K. A controlled trial of methadone in a population of intravenous drug users in Bangkok: implications for prevention of HIV. International Journal of the Addictions 1991;26(12):1313-20.

16. Gruber VA, Delucchi KL, Kielstein A, Batki SL. A randomised trial of 6-month methadone maintenance with standard or minimal counselling versus 21-day methadone detoxification.. Drug andAlcohol Dependence 2008;94:199-206.

17. Sees KL, Delucchi KL, Masson C, Rosen A, Clark HW, Robillard $\mathbf{H}$, et al. Methadone maintenance vs 180-day psychosocially enriched detoxification for treatment of opioid dependence. A randomised controlled trial. Journal of the American Medical Association 2000; 283(10):1303-10.

18. Ward J, Mattick R P, Hall W. Key issues in methadone maintenance treatment. Sydney: New South Wales University Press, 1992.

19. Jaffe, J. Drug addiction and drug abuse. In: A Gilman, T Rall, A Nies, P Taylor editor(s). The pharmacological basis of therapeutics. 8th Edition. New York: Pergamon Press, 1990:522-73.

20. Panga L, Haob Y, Mia G, Wanga C, Luoa W, Roua K, Lic J, Wu Z. Effectiveness of first eight methadone maintenance treatment clinics in China.

21. Zhao Y, Shi CX, McGoogan JM, Rou K, Zhang F, Wu Z. Methadone maintenance treatment and mortality in HIV-positive people who inject opioids in China. World Health Organization (Bulletin) 2013;91:93-101

22. Lu WJ, Zhou W, Kreutz Y, Flockhart DA, Lu et al. Methadone adverse reaction presenting with large increase in plasma methadone binding. A case series Journal of Medical Case Reports $2011,5: 513$

23. Farre M, Mas A, Moreno V, Camí J. Retention rate and illicit opioid use during methadone maintenance interventions: A meta-analysis. Drug and Alcohol Dependence. 2002;65(3):283-290. [PubMed]

24. Ward J, Mattick RP, Hall W. Methadone maintenance treatment and other opioid replacement therapies. Overseas Publishers Association, Harwood Academic Publishers; 1998. pp. 205-238.

25. Strain EC, Stitzer ML. Methadone treatment for opioid dependence. Baltimore, MD: The John Hopkins University Press; 1999.

26. Booth RE, Corsi KF, Mikulich-Gilbertson SK. Factors associated with methadone maintenance treatment retention among street-recruited 
injection drug users. Drug and Alcohol Dependence. 2004;74(2):177-185. [PubMed]

27. D'Ippoliti D, Davoli M, Perucci CA, Pasqualini F, Bargagli AM. Retention in treatment of heroin users in Italy: The role of treatment type and of methadone maintenance dosage. Drug and Alcohol Dependence. 1998;52(2):167-171. [PubMed]
28. Faggiano F, Vigna-Taglianti F, Versino E, Lemma P. Methadone maintenance at different dosages for opioid dependence. Cochrane Database System Review. 2003;3:CD 002208.

29. Brady TM, Salvucci S, Sverdlov LS, Male A, Kyeyune H, Sikali E, et al. Methadone dosage and retention: An examination of the $60 \mathrm{mg} /$ day threshold. Journal of Addictive Diseases. 2005; 24(3):23-47. [PubMed]

Address of Correspondence: Kabin Man Dangol, Teaching Assistant, Department of Psychiatry \& Mental Health, Institute of Medicine, email: kabinmand@yahoo.com 